\title{
A PROOF OF THE MARKOV-KAKUTANI THEOREM ON NONCOMPACT SET VIA ZERMELO'S WELL-ORDERING THEOREM
}

\author{
ISSA MOHAMADI AND SHAHRAM SAEIDI \\ Department of Mathematics, University of Kurdistan \\ Sanandaj 416, Iran \\ E-mail: shahram_saeidi@yahoo.com, sh.saeidi@uok.ac.ir
}

\begin{abstract}
The Markov-Kakutani fixed point theorem has been considered as one of the most remarkable theorems due to considerable diversity in its applications in the history of functional analysis. Different approaches have been investigated to prove this theorem; however, the condition of compactness of the underlying set is essentially used. In this paper, we develop a new method, based on Zermelo's well-ordering theorem, to weaken the compactness condition.

Key Words and Phrases: Affine mapping, the Markov-Kakutani fixed point theorem, Zermelo's well-ordering theorem.
\end{abstract}

2010 Mathematics Subject Classification: 47H20, 47H10.

Acknowledgments. This work was carried out while the first author was visiting the Department of Mathematical and Statistical Sciences of the University of Alberta. He thanks them for their kind hospitality. The authors would like to thank the referee for helpful comments.

\section{REFERENCES}

[1] N. Adasch, B. Ernst and D. Keim, Topological Vector Spaces, The Theory Without Convexity Conditions, Lecture Notes in Mathematics 639, Springer-Verlag, New York, 1978.

[2] M.M. Day, Fixed-point theorem for compact convex sets, Illinois J. Math., 5(1961), 585-590.

[3] M.M. Day, Semigroups and amenability, In: 1969 Semigroups (Proc. Sympos. Wayne State Univ., Detroit, Mich., 1968), Academic Press, 1969, New York, 5-53.

[4] M.M. Day, The spaces $L^{p}$ with $0<p<1$, Bull. Amer. Math. Soc., 46(1940), 816-823.

[5] S. Kakutani, Two fixed-point theorems concerning bicompact convex sets, Proc. Imp. Acad., 14(1938), 27-31.

[6] A. Markov, Quelques theoremes sur ensembles abeliens, C.R. (Doklady) Acad. Sci. URSS N.S., 1(1936), 311-313.

[7] W. Rudin, Functional Analysis, 2nd edition, McGraw-Hill, New York, 1991.

[8] W. Takahashi, A convexity in metric space and nonexpansive mappings, Kodai Math. Semin. Rep., 22(1970), 142-149.

Received: February 26, 2015; Accepted: May 10, 2015. 
